\title{
Characteristics of lead-acid and nickel metal hydride batteries in uninterruptible power supply operation
}

\author{
Nurshahirah Athirah Rohman', Nor Farahaida Abdul Rahman², \\ Muhammad Ammirrul Atiqi Mohd Zainuri ${ }^{3}$ \\ ${ }^{1,2}$ Faculty of Electrical Engineering, Universiti Teknologi MARA, Malaysia \\ ${ }^{3}$ School of Electrical \& Electronic Engineering, Universiti Sains Malaysia, Malaysia
}

\begin{tabular}{l} 
Article Info \\
Article history: \\
Received Nov 7, 2018 \\
Revised Jan 29, 2019 \\
Accepted Mar 18, 2019 \\
\hline Keywords: \\
Uninterruptable power supply \\
(UPSs) \\
Nickel metal hydride (NiMH) \\
Power Quality (PQ) \\
lead-acid battery \\
State of Charge (SOC)
\end{tabular}

\section{Corresponding Author:}

Nor Farahaida Abdul Rahman, Faculty of Electrical Engineering, Universiti Teknologi MARA, 40450 Shah Alam, Selangor Darul Ehsan, Malaysia. Email: farahaida@salam.uitm.edu.my

\begin{abstract}
Batteries are one of the main elements in Uninterruptable Power Supply (UPSs). To maintain good operation during power failure, UPSs must have adequate energy for their operation. It depends on the reliability and performance of batteries. Owing to low capital cost and wide availability, lead-acid batteries have been used extensively as the main energy source in UPSs. Nevertheless, as batteries technology grown, Nickel Metal Hydride (NiMH) batteries have offered more promising performance than lead-acid batteries; they are installed in various portable electronic devices. This paper provides an overview of the performance of lead-acid and NiMH batteries during the operation of a single-phase UPS. Their performances are studied based on 2 characteristics which are discharge curve and State of Charge (SOC). Based on those characteristics, both batteries have shown different performances. Simulation results have shown that the NiMH battery exhibits better discharge curve with higher voltage capacity and constant discharge current, and it is more reliable to obtain $12 \mathrm{~V}$ at minimum percentage of SOC than the lead-acid battery.
\end{abstract}

Copyright (C) 2019 Institute of Advanced Engineering and Science. All rights reserved.

\section{INTRODUCTION}

Power Quality (PQ) problem is a term to define any deviation of voltage, current or frequency that interferes normal operation of electrical equipment [1]. Common types of PQ problems are voltage/current sags/ swells/ variations, transients, interruptions and harmonics.

Interruption (or power failure) refers to a time period when electricity supply of a building is interrupted due to circuit breaker tripping or power distribution failure. To safeguard the building against power interruption, an Uninterruptible Power Supply (UPS) can be introduced [2-4]. The UPS is developed to provide uninterrupted, high quality and reliable backup power to electrical loads [5-7].

Normally, lead-acid batteries are used as the primary voltage source for UPS system [8]. For many years, lead-acid batteries have been widely employed and recognized as the most reliable means of preserving electrical power during interruption of power supply [9]. Additionally, low capital cost, wide availability and mature technology are the other reason why lead-acid batteries become the most favourite choice in many residential applications, even though it inherits low cycle life characteristic [10-12]. In [13], Schaetzle. H. J and Boden D. P have mentioned that the maximum cycle life of lead-acid batteries is about 1000 to 1200 cycles which are 3 to 5 years; it is based on how frequently they are used in surrounding temperature. Furthermore, in the next two decades, lead-acid batteries are also predicted to remain cheaper 
than their alternatives [14]. Hence, most of researches have shown more interest in using lead-acid batteries in UPSs than using other types of batteries.

Meanwhile, Nickel Metal Hydride (NiMH) batteries are getting more attention due to their usage in portable/backup power systems [15] and UPSs. According to Tarabay. J, Karami. N in [16], NiMH batteries are recommended to be accepted in several portable electronic devices and electric vehicle applications. There are many benefits of using NiMH batteries which involving their energy density and life cycle [17-20]. Generally, the life age of NiMH batteries is restricted to 5 years, and they can be recharged for more than hundred times.

Since both batteries inherit different construction and operation, choosing a battery that can match requirements of UPS operation is tricky. Hence, a clear description of battery characteristics is very important; to choose the most suitable battery that can maximize the UPS operation for long terms. The main purpose of this work is to analyse the performance of lead-acid and NiMH batteries in a single-phase UPS operation using MATLAB/Simulink. Their performances are assessed based on their discharging curves (at different current rates), and State of Charge (SOC) characteristics only.

The organization of this paper is as follows: I) Introduction, II) Methodology, III) Results and Discussions, and IV) Conclusion.

\section{RESEARCH METHOD}

The work starts by generating discharge curves of lead-acid and $\mathrm{NiMH}$ batteries using battery models in MATLAB/Simulink. Each discharge curve is produced using $0.2 \mathrm{C}, 0.5 \mathrm{C}, 1 \mathrm{C}$ and $2 \mathrm{C}$ current rate (C-rate) at nominal voltage of $12 \mathrm{~V}$ and $8.2 \mathrm{Ah}$ battery capacity. C-rate indicates the current in which the battery starts to discharge. In other word, $0.2 \mathrm{C}$ or $\mathrm{C} / 5$ is known as a 5 -hour discharge, $0.5 \mathrm{C}$ or $\mathrm{C} / 2$ is a 2 -hour discharge, $1 \mathrm{C}$ is a 1-hour discharge, and $2 \mathrm{C}$ is a 30 -minute discharge. An example of a nominal discharge curve of a battery is shown in Figure 1.

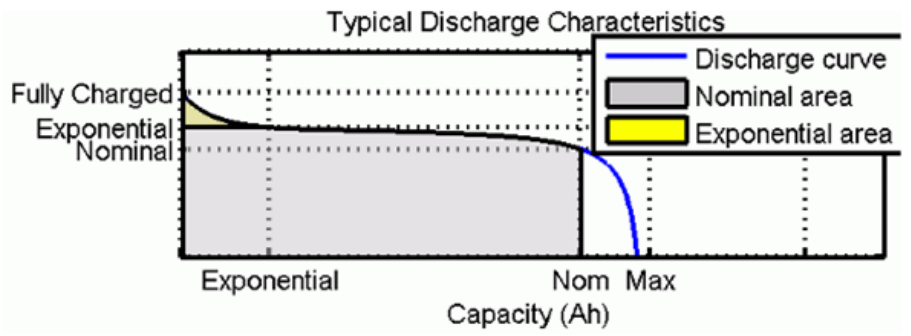

Figure 1. Nominal discharge curve of battery

Based on the curve, there are 3 important data specifications should be considered: nominal voltage, rated capacity and SOC. The SOC is known as an indication of the quantity of electricity that available in a battery in relation to its practical capacity with the given past and future discharge conditions [21, 22]. In this study, the same data parameters are used for both lead-acid and NiMH batteries to find the differences of characteristics between these two types of batteries.

Next, both batteries are employed in a $230 \mathrm{~V}, 50 \mathrm{~Hz}$ single-phase UPS. The simulation circuit of the UPS system is depicted in Figure 2. As shown, a $12 \mathrm{~V}$ lead-acid or NiMH battery together with a DC-link capacitor $\mathrm{C} 1$ are connected between a single-phase uncontrollable full bridge rectifier and a single-phase controllable full bridge inverter. The battery is labelled as B. In this work, an RLC filter is used to filter the output voltage and current of the UPS.

In general, the full bridge rectifier is used to convert AC voltage to DC voltage. Then, the $12 \mathrm{~V}$ leadacid or NiMH rechargeable battery is utilized to supply voltage during the backup time. On the other hand, the full bridge inverter is responsible to convert DC voltage to AC voltage desired by the load [23].

In normal operation, $\mathrm{AC}$ power to the load is continuously supplied through the rectifier and inverter. The rectifier is responsible to charge the battery and supply power to the load through the inverter. When interruption occur, the battery and inverter maintain to supply power to the load. A bypass switch is also be used to provide AC current path directly to the load, during the overload of the AC supply or the failure of the inverter. Overload happens when the load power demand is greater than the UPS rating, and typically can destroy the UPS. In this work, a Proportional Integral (PI) controller is used to control the output voltage of the UPS system.

Characteristics of lead-acid and nickel metal hydride batteries in ... (Nor Farahaida Abdul Rahman) 
The performance of lead-acid and NiMH batteries in the UPS system is determined using the relationship between voltage and SOC. Ideally, SOC of a fully charged battery is $100 \%$, while SOC of a fully depleted battery is $0 \%$. Normally, the actual voltage of $12 \mathrm{~V}$ battery is higher than its nominal voltage, and the range is around $10 \%$ to $20 \%$. This is because, the battery with desired $12 \mathrm{~V}$ has less than $100 \%$ of SOC. Therefore, the performance of lead-acid and NiMH batteries will be compared regarding to their reliability to obtain $12 \mathrm{~V}$ at minimum SOC. Besides, the length of time for charging process also being considered.

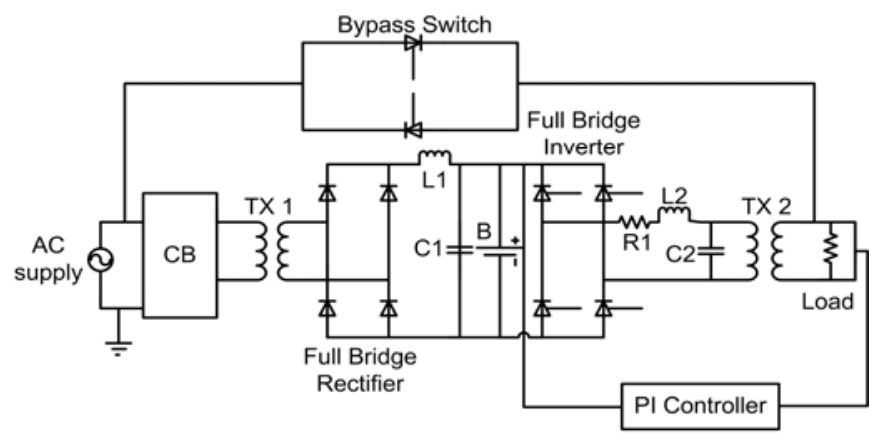

Figure 2. Simulation circuit of UPS

\section{RESULTS AND DISCUSSION}

This section presents and discusses about battery parameters used in the simulation work, characteristics of discharging curves, UPS simulation results and SOC for lead-acid and NiMH rechargeable batteries.

\subsection{Battery parameters}

Table 1 shows all specifications of lead-acid and NiMH batteries which have been used for determining their performance behaviour. The nominal voltage represents the linear zone of discharge characteristics. The rated capacity is the minimum effective capacity of the battery that represented by the value in Ampere-hour (Ah). On the other hand, the initial SOC indicates the charge level for each battery.

Table 1. Parameters of lead-acid and NiMH batteries

\begin{tabular}{lll}
\hline Parameter & Lead-acid & NiMH \\
\hline Nominal voltage (V) & 12 & 12 \\
Rated capacity (Ah) & 8.2 & 8.2 \\
Initial SOC percentage (\%) & 100 & 100 \\
\multicolumn{2}{c}{ Parameter Based on Battery } & Type and Nominal Value \\
Maximum capacity (Ah) & 8.54 & 8.83 \\
Fully charged voltage (V) & 13.07 & 14.14 \\
Nominal discharge current (A) & 1.64 & 1.64 \\
Internal resistance (Ohms) & 0.015 & 0.015 \\
Capacity (Ah) & 2.54 & 7.88 \\
Exponential zone [V, Ah] & {$[12.22,0.03]$} & {$[13.02,1.64]$} \\
\hline
\end{tabular}

\subsection{Nominal discharge curve of lead-acid battery}

Figure 3(a) and (b) display the overall and the exponential area of lead-acid battery's discharge curve at $0.2 \mathrm{C}$ respectively. The curve presents the relationship between battery capacity and discharge current at specific C-rated. As shown in Figure. 3(a), the nominal discharge current is $20 \%$ of the rated battery capacity which is $1.64 \mathrm{~A}$. It means that the $8.2 \mathrm{Ah}$ lead-acid battery provides $1.64 \mathrm{~A}$ for 5 hours if discharged at $0.2 \mathrm{C}$ rate. The discharge current can be calculated using $\mathrm{C}$-rated $(\mathrm{C}) \times$ rated capacity $(\mathrm{Ah}) / 1$ hour $=$ current $(\mathrm{A})$.

Int J Pow Elec \& Dri Syst, Vol. 10, No. 3, Sep 2019 : 1520 - 1528 


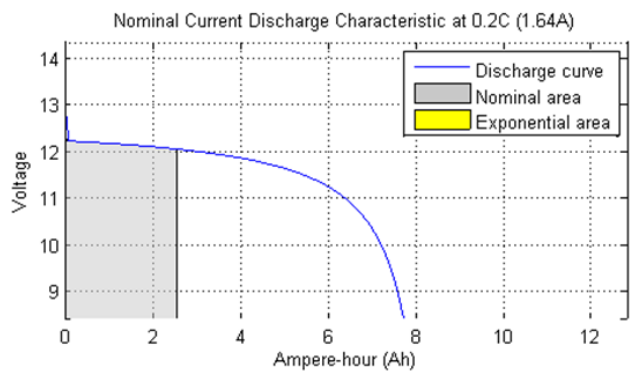

(a)

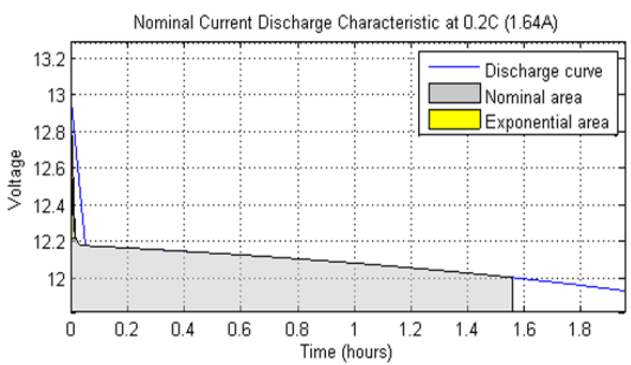

(b)

Figure 3. (a) Discharge curve and (b) exponential area of lead-acid battery at $0.2 \mathrm{C}$

Based on the exponential area shown in Figure 3(b), the battery voltage decreases from $13.07 \mathrm{~V}$ to 12.22 V. Meanwhile, the nominal area shown in Figure. 3(a) has revealed that the total charge (or capacity) that can be extracted from the lead-acid battery is 2.54 Ah before the discharge process stops, when the tension drops off.

Figure 4 depicts 4 discharge curves of the battery at different C-rates. Each curve represents a different discharge current value $(1.64 \mathrm{~A}, 4.1 \mathrm{~A}, 8.2 \mathrm{~A}$ or $16.4 \mathrm{~A})$. The figure has clearly shown that the battery capacity is directly affected by the discharge currents. If the battery is discharged at higher current, the quantity of available capacity of electricity becomes low. In contrast, a lower discharge current will cause the quantity of available capacity of battery electricity increases in the range of $3 \%$ to $19 \%$. Therefore, by discharging the battery at higher current will cause the battery capacity and life span decrease.

Figure 5 displays time taken to discharge the lead-acid battery at different C-rates. At the highest discharge current of $16.4 \mathrm{~A}$, the battery takes 22 minutes to complete the discharge process. However, at the lowest discharge current of $1.64 \mathrm{~A}$, it takes 4 hours and 36 minutes to complete the discharge process. Hence, the difference of discharge time at highest and lowerst discharge currents is approximately $92 \%$.

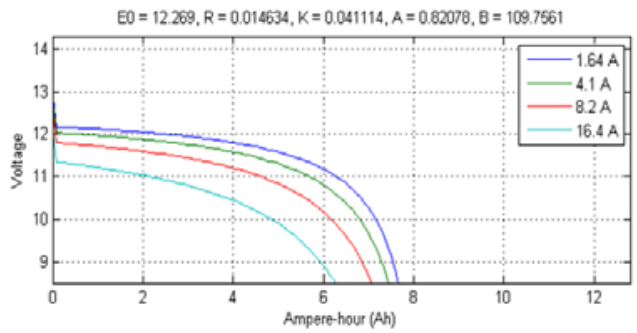

Figure 4. Discharge curves of lead-acid battery at different C-rates

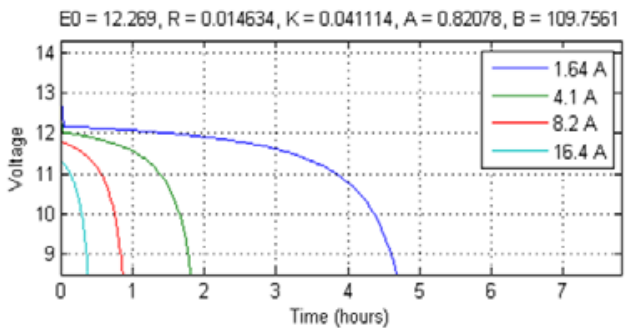

Figure 5. Time taken to discharge lead-acid battery at different C-rates

\subsection{Nominal discharge curve of NiMH battery}

Discharge curve of the NiMH battery at $0.2 \mathrm{C}$ is shown in Figure. $6(\mathrm{a})$. According to the exponential area, voltage of the NiMH battery drops from $14.14 \mathrm{~V}$ to $13.02 \mathrm{~V}$ during the discharging process. Meanwhile, the total charge (or capacity) that can be extracted from the NiMH battery is $6.73 \mathrm{Ah}$.

Figure. 6(b) depicts 4 discharge curves of the NiMH battery at specified C-rates. Each curve represents different discharge currents (which are 1.64 A, 4.1 A, 8.2 A and 16.4 A) with battery capacity of 8.2 Ah. As similar as the lead-acid battery, the figure has proven that the higher the discharge current, the lower quantity of electricity produced by the NiMH battery.

Additionally, Figure. 7 shows time taken to discharge the NiMH battery at 4 different values of Crates. Based on the figure, the battery takes 29 minutes to complete the discharge process of the highest discharge current (16.4 A). Instead, it takes 5 hours 9 minutes to complete the discharge process of the lowest discharge current $(1.64 \mathrm{~A})$. Therefore, the difference of time taken to complete the discharging process between the highest and lowest discharge currents is about $90 \%$.

Based on all results, it can be verified that the discharge time of the lead-acid battery is faster than the NiMH battery; the faster the discharge process, the greater the fall in capacity. Thus, the capacity of the

Characteristics of lead-acid and nickel metal hydride batteries in ... (Nor Farahaida Abdul Rahman) 
lead-acid battery is lower than the NiMH battery. The advantage of having longer discharge time is that the sulfuric acid in the battery can return to the pores easily via diffusion. Therefore, an asymptote on the capacity-discharge time curve that indicates the maximum possible capacity can be obtained [24]. Based on the discharging time of both batteries, the NiMH battery shows more promising performance in the UPS system than the lead-acid battery.

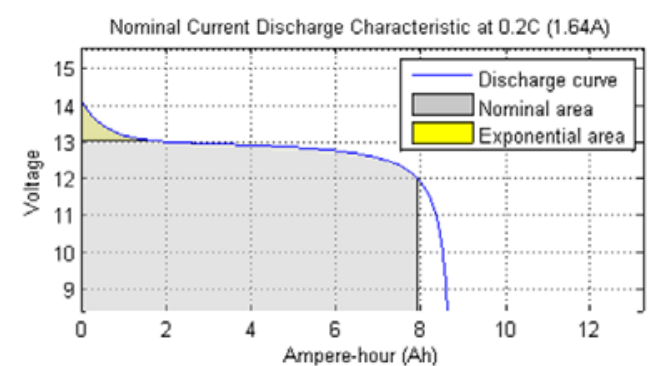

(a)

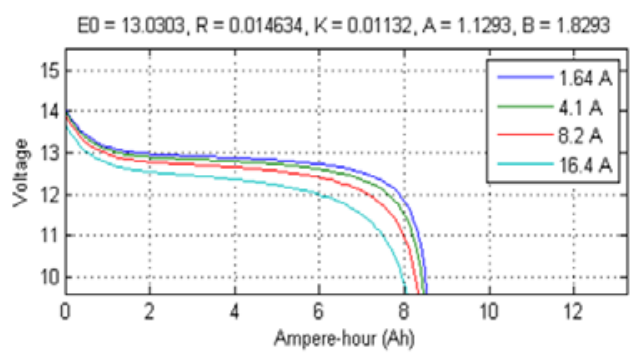

(b)

Figure 6. Discharge curve of NiMH battery at (a) $0.2 \mathrm{C}$ and (b) different C-rates

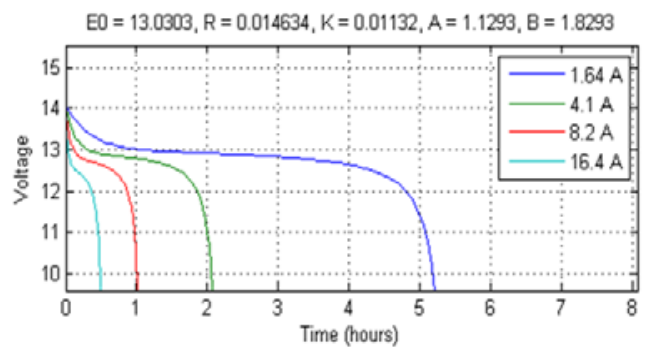

Figure 7. Time taken to discharge NiMH battery at different C-rates

\subsection{Simulation results of single-phase UPS system}

All simulation results are obtained to demonstrate the output waveform the UPS. Figure. 8(a) presents an AC voltage waveform supplied to the UPS. The voltage amplitude is $325.27 \mathrm{~V}$ which is equals to $230 \mathrm{~V}(\mathrm{rms})$ supply voltage. Additionally, Figure. 8(b) and Figure. 9(a) show waveforms of supply voltage of the rectifier at the secondary winding of a step-down transformer 1 (TX 1), and output voltage of the inverter at the primary winding of a step-up transformer 2 (TX 2) respectively. From $0.03 \mathrm{~s}$ to $0.06 \mathrm{~s}$, the supply voltage shown in Figure. $8(\mathrm{~b})$ is equal to zero; it is due to the Circuit Breaker (CB) operation to create voltage interruption. During this time, the battery acts as a secondary voltage source and supplies power to the inverter without any interruption. As a result, Figure. 9(a) depicts that the output voltage of the inverter between $0.03 \mathrm{~s}$ to $0.06 \mathrm{~s}$ exhibits a sinusoidal waveform with an amplitude of $12 \mathrm{~V}$.

Figure. 9(b) presents an output voltage waveform of the inverter at the secondary winding of TX 2. The amplitude of the output voltage is equal to $325.27 \mathrm{~V}$ or $230 \mathrm{~V}(\mathrm{rms})$ after being stepped up by TX 2; to maintain the supply voltage as same as the AC supply. In between $0.03 \mathrm{~s}$ and $0.06 \mathrm{~s}$, the interruption as shown as in Figure. 8(b) is still occurs, but the $12 \mathrm{~V}$ battery has successfully supplied $230 \mathrm{~V}$ to the connected load without any interruption. Therefore, these results have proven the reliability of the UPS system in supplying $230 \mathrm{~V}$ to the load using $12 \mathrm{~V}$ rechargeable battery. Thus, a continuous operation of the load can be achieved. 


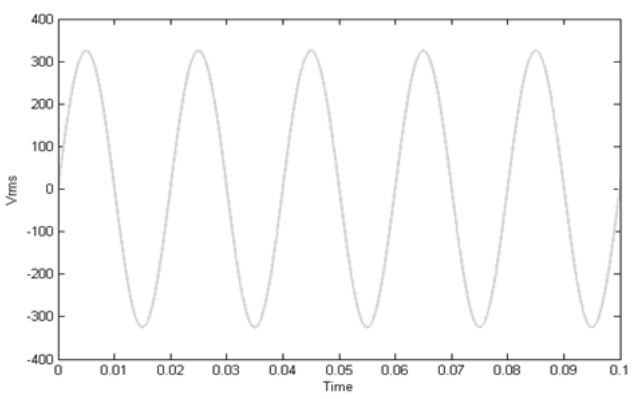

(a)

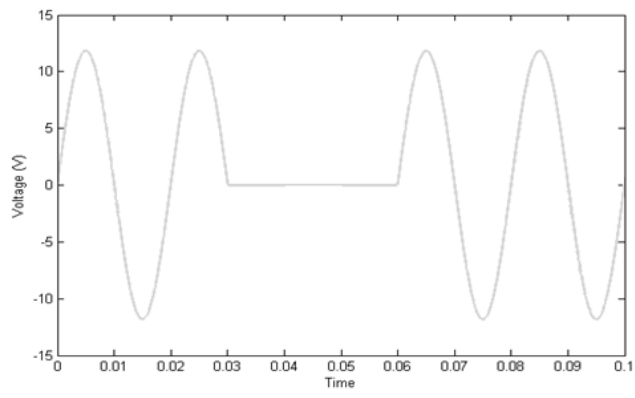

(b)

Figure 8. Waveforms of (a) AC voltage supplied to UPS system and (b) voltage at the secondary winding of TX 1 and rectifier

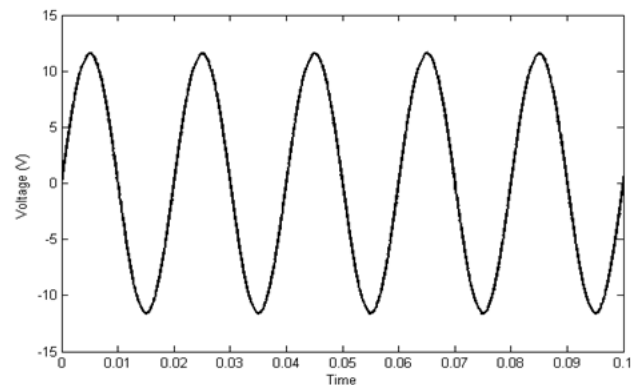

(a)

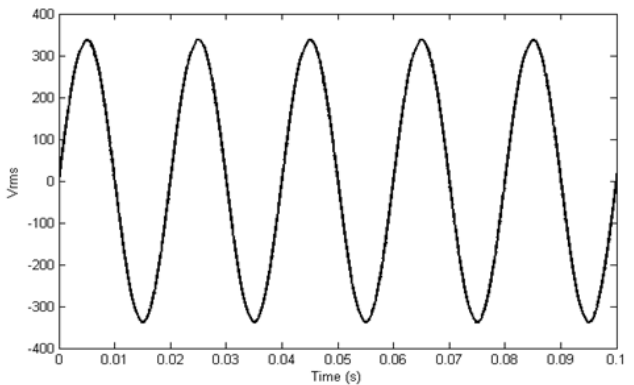

(b)

Figure 9. Waveforms of output voltage at (a) the primary winding of TX 2 and (b) the secondary winding of TX 2 and load

\subsection{SOC of lead-acid and NiMH batteries}

According to Wen-Yeau Chang in [25], SOC is a very important parameter to describe the remaining capacity of a battery. Information about SOC is used in Battery Control Strategy (BMS) to ensure rechargeable batteries inherit proper charging and discharging processes without subjecting them to conditions outside of their safe operating limits. SOC not only to protect and improve batteries life cycle and prevent over discharge, but also allow to make good control strategies to fully utilize their energy.

Figure. 10(a) and (b) depict results of the lead-acid battery charged at $100 \%$ and $25 \%$ of SOC, at a constant $0.2 \mathrm{C}$ rate during running load. The results show the difference in obtaining the voltage of the battery at difference levels of SOC. At $100 \%$ of SOC, the lead-acid battery obtains $13.41 \mathrm{~V}$. Meanwhile at $25 \%$ of $\mathrm{SOC}$, the battery only obtains $11.50 \mathrm{~V}$ which is lower than the nominal voltage $(12 \mathrm{~V})$.
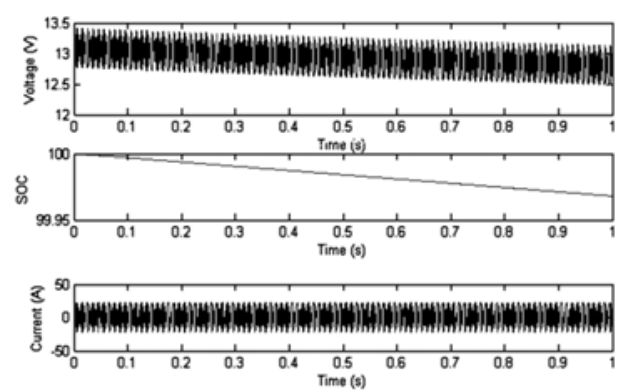

(a)
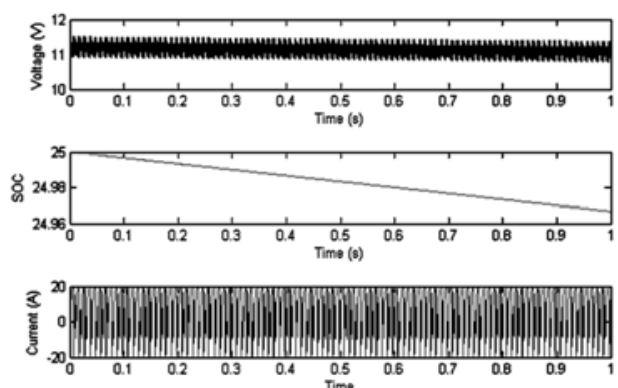

(b)

Figure 10. (a) $100 \%$ and (b) $25 \%$ SOC of lead-acid battery 
Figure. 11(a) and (b) present results of the NiMH battery charged at $100 \%$ and $25 \%$ level of SOC, at a constant $0.2 \mathrm{C}$ rate during running load. At $100 \%$ of SOC, the NiMH battery obtains $14.48 \mathrm{~V}$. Meanwhile, at $25 \%$ of SOC the battery obtains $13 \mathrm{~V}$ which is higher than its nominal voltage $(12 \mathrm{~V})$.
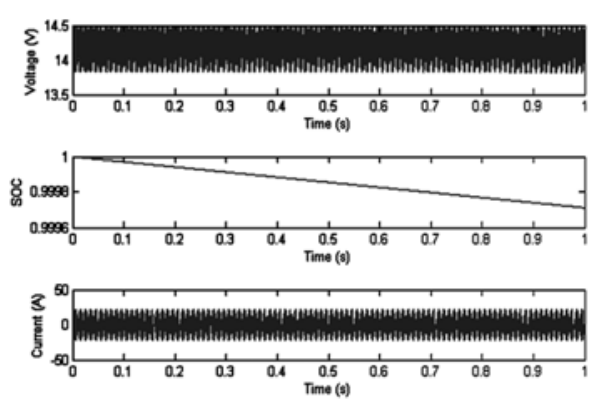

(a)
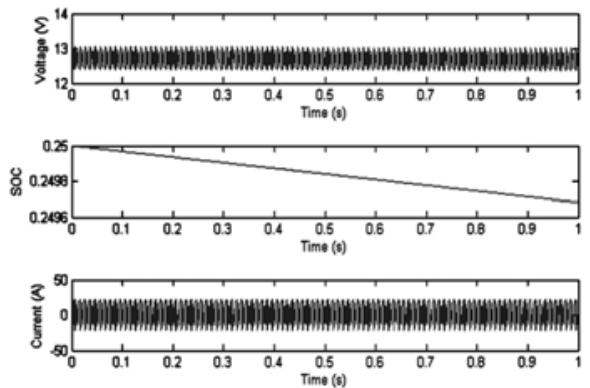

(b)

Figure 11. (a) 100\% and (b) SOC of NiMH battery

Table 2 tabulates all voltages of the lead-acid and NiMH batteries at difference levels of SOC. Based on the table, as the level of SOC reduces, the voltage of the lead-acid battery drops gradually. The minimum level of SOC for the battery to produce $12 \mathrm{~V}$ is $45 \%$. Similarly, the results have shown that the voltage of the NiMH battery also drops slowly. Nevertheless, the minimum level of SOC to obtain $12 \mathrm{~V}$ is $8 \%$; it is $37 \%$ lower than the lead-acid battery. As a result, the NiMH battery exhibits faster charging process than the lead-acid; to obtain $12 \mathrm{~V}$.

Based on the results, it can be observed that the NiMH battery is more reliable to obtain $12 \mathrm{~V}$ at minimum percentage of SOC as compared to the lead-acid battery. Besides, from Table 2, it shows that the NiMH battery only needs $8 \%$ of SOC to obtain $12 \mathrm{~V}$, and it takes shorter time for charging process than the lead-acid battery that needs $45 \%$ of SOC. Therefore, based on the SOC results for both batteries, the NiMH battery shows better SOC characteristics than the lead-acid battery, and hence, it is more suitable to be used in the UPS system.

Table 2. SOC estimation of lead-acid and NiMH batteries

\begin{tabular}{lll}
\hline \multirow{2}{*}{ SOC $\%$} & $\begin{array}{l}\text { Lead-acid } \\
\text { Voltage }(\mathrm{V})\end{array}$ & $\begin{array}{l}\text { NiMH } \\
\text { Voltage }(\mathrm{V})\end{array}$ \\
\hline 100 & 13.41 & 14.48 \\
75 & 12.46 & 13.33 \\
50 & 12.22 & 13.24 \\
45 & 12.00 & 13.00 \\
25 & 11.50 & 12.00 \\
\hline
\end{tabular}

\section{CONCLUSION}

According to the simulation results, both lead-acid and NiMH batteries have shown difference characteristics in UPS operation. The NiMH battery exhibits better performance than the lead-acid battery in term of discharging characteristics, and SOC and voltage relationships. For discharging process, the NiMH battery has proven that the capacity of the battery is higher for every constant of discharge current as compared to the lead-acid battery, which has lower capacity between $10 \%$ to $23 \%$. In addition, the time taken for the NiMH battery to complete its discharging process is longer than the lead-acid battery. Hence, it inherits higher capacity. Furthermore, based on the SOC results, the reliability of the NiMH battery to obtain $12 \mathrm{~V}$ at minimum percentage of SOC is lower than the lead -acid battery. Thus, the time taken for charging process becomes faster. Based on all results, it can be concluded that the NiMH battery is more suitable to be used in the single-phase UPS system than the lead-acid battery.

\section{ACKNOWLEDGEMENTS}

This work is supported by Universiti Teknologi MARA under the Dana Bistari Grant, project 600IRMI/DANA 5/3/BESTARI (121/2018).

Int J Pow Elec \& Dri Syst, Vol. 10, No. 3, Sep 2019 : 1520 - 1528 


\section{REFERENCES}

[1] M. F. Hordeski, "Emergency and Backup Power Sources: Preparing for Blackouts and Brownouts", Indian Trail Lilburn: The Fairmont Press, Inc, 2005.

[2] M. Najib and N. Azila, "Power Electronics Power Semiconductors, Converters and Applications", University Publication Centre (UPENA), UiTM Shah Alam, 2010.

[3] M. Ali, M. Aamir, H. S. Khan, A. W., F. Haroon and A. R. Jafri,"Lyapunov Stability and Performance Analysis of the Fractional Order Sliding Mode Control for a Parallel Connected UPS System under Unbalanced and Nonlinear Load Conditions", Energies, vol. 11, issue 12, pp. 3475, 2018.

[4] Dmitry A. S., Andrey V. G., Dmitry V. K., Maxim V. B., Alexander N. R., Viacheslav S. K.,'Uninterruptible Power System with Parallel Operation of AC/DC and DC/DC Converters", Proc. of the 16th International Conference of Young Specialists on Micro/Nanotechnologies and Electron Devices, pp. 508-513, 2015.

[5] J. Platts and J. S. Aubyn, Eds., "Uninterruptible Power Supplies", 2nd Edition. London, United Kingdom: The Institution of Engineering and Technology, London, United Kingdom, 2007.

[6] T. J. C. Sousa, V. Monteiro, J. G. Pinto, A. A. N. Meléndez and J. L. Afonso, "Single-phase shunt active power filter with UPS operation using a bidirectional Dc-Dc converter for energy storage interface," Proc. of the 43rd IEEE Industrial Electronics Society Annual Conference, pp. 4972-4977, 2017.

[7] Y. Tang, W. Yao and F. Blaabjerg, "A Dual Mode Operated Boost Inverter and Its Control Strategy for Ripple Current Reduction in Single-Phase Uninterruptible Power Supplies," Proc. of the 9th International Conference on Power Electronics and ECCE Asia, pp. 2227-2234, 2015.

[8] A.-I. Stan, M. Swierczynski, D.-I. Stroe, R. Teodorescu, S. J. Andreasen, and K. Moth, "A Comparative Study of Lithium Ion to Lead Acid Batteries for Use in UPS Applications," Proc. of the IEEE 36th Telecommunication Energy Conference, pp. 1-8, 2014.

[9] Yunsong W. and Tao Cai," Model of Uninterruptible Power Supply Based on Improved Hopfield Network", Rev. Téc. Ing. Univ. Zulia. vol. 39, no. 11, pp. 10-14, 2016.

[10] V. A. Boicea, "Energy Storage Technologies: The Past and The Present," Proc. of the IEEE, vol. 102, no. 11, pp. 1777-1794, 2014.

[11] H. Ibrahim, A. Ilinca, and J. Perron, "Energy Storage Systems - Characteristics and Comparisons," Renewable Sustainable Energy Rev., vol. 12, no. 5, pp. 1221-1250, 2008.

[12] Chen, S., Lian, Z., Li, S., Kim, J., Li, Y., Cao, L., Liu, Z., "The Environmental Burdens of Lead-Acid Batteries in China: Insights From an Integrated Material Flow Analysis and Life Cycle Assessment of Lead", Energies, vol. 10, no. 12, pp. 1969, 2017.

[13] Schaetzle H.J. and Boden D.P., J. Power Sources, 4, pp. 327-336, 1979.

[14] S. Matteson and E. Williams, "Residual Learning Rates in Lead-Acid Batteries: Effects on Emerging Technologies," Energy Policy, vol. 85, pp. 71-79, 2015.

[15] J. Tarabay and N. Karami, "Nickel Metal Hydride Battery: Structure, Chemical Reaction, and Circuit Model," Proc. of the Third International Conference on Technological Advances in Electrical, Electronics and Computer Engineering, pp. 22-26, 2015.

[16] J. Tarabay and N. Karami, "Nickel Metal Hydride Battery: Structure, Chemical Reaction, and Circuit Model," 2015 Third International Conference on Technological Advances in Electrical, Electronics and Computer Engineering, pp. 22-26, 2015.

[17] Ozdemir, A.T., Ustkoyuncu, N., Bakoglu, N.U., Ozsoy, F., Patat, S.,’Temperature Effects on Calendar Agingof Lithium-Ion and Nickel Metal Hydride Batteries", Proc. of the 1st International Conference on Design, Engineering and Computer Science, vol. 453, no 1, 2018.

[18] M.A. Fetcenko, S.R. Ovshinsky, B. Reichman, K. Young, C. Fierro, J. Koch, A. Zallen, W. Mays, T. Ouchi, "Recent Advances in NiMH Battery Technology", Journal of Power Sources, vol. 165, pp. 544-551, 2007.

[19] F. Boico, B. Lehman and K. Shujaee, "Solar Battery Chargers for NiMH Batteries," IEEE Transactions on Power Electronics, vol. 22, no. 5, pp. 1600-1609, 2007.

[20] T.-K. Ying, X.-P. Gao, W.-K. Hu, F. Wu, D. Noréus, "Studies on Rechargeable NiMH Batteries", International Journal of Hydrogen Energy, vol. 31, pp. 525-530, 2006.

[21] N. Bashir, H. S. Sardar, M. Nasir, N. U. Hassan and H. A. Khan, "Lifetime Maximization of Lead-Acid Batteries in Small Scale UPS and Distributed Generation Systems," Proc. of the IEEE Manchester PowerTech, pp. 1-6, 2017.

[22] Changhao Piao, Xiaoyong Yang, Cong Teng and HuiQian Yang, "An Improved Model Based on Artificial Neural Networks and Thevenin Model for Nickel Metal Hydride Power Battery," Proc. of the International Conference on Optics, Photonics and Energy Engineering, pp. 115-118, 2010.

[23] X. Y. Zhang, X. H. Zhang, L. Li, F. Luo and Y. S. Zhang,” A New Cascaded Control Strategy for Paralleled LineInteractive UPS with LCL Filter", Proc. of the International Conference on New Energy and Future Energy System, vol. 40, no. 1, 2016.

[24] G. S. Glaize Christian, "Lead and Nickel Electrochemical Batteries", 1st ed. Great Britain and United States: ISTE Ltd and John Wiley, 2012.

[25] N. E. Dunbar and C. Segrin, "International Scholarly Research Notices," ISRN Educ., vol. 2012, no. i, pp. 1-9, 2012.

\section{BIOGRAPHIES OF AUTHORS}

Characteristics of lead-acid and nickel metal hydride batteries in ... (Nor Farahaida Abdul Rahman) 


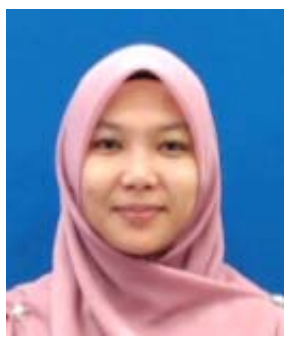

Nurshahirah Athirah Rohman was born in Kuala Lumpur, Malaysia, in 1994. She received her B. Eng (Hons) from Universiti Teknologi MARA (UiTM) Malaysia. Her research interests are Uninterruptable Power Supply (UPS).

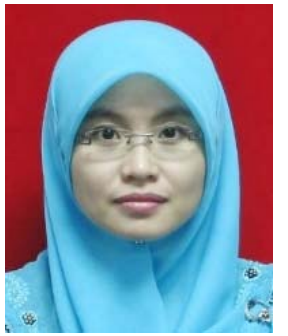

Nor Farahaida Abdul Rahman was born in Selangor, Malaysia, in 1980. She received her B.Eng. (Hons.) and M.Eng. degrees from Universiti Teknologi Malaysia (UTM), Skudai, Johor, Malaysia, and PhD in Power Engineering from Universiti Putra Malaysia (UPM). She is currently a senior lecturer at Centre of Power Engineering Studies, Faculty of Electrical Engineering, Universiti Teknologi Mara (UiTM). Her research interests are active filters, power qualities and power electronics.

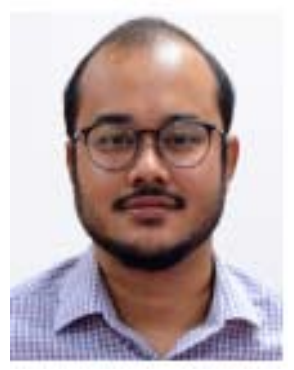

Muhammad Ammirrul Atiqi Mohd Zainuri received his B. Eng (Hons), M. Sc and PhD from Universiti Putra Malaysia (UPM), Malaysia. He is a senior lecturer at Electrical Engineering Programme, School of Electrical and Electronic Engineering, Engineering Campus, Universiti Sains Malaysia. His research interests are power electronics, controls in power electronics, power quality, renewable energy systems, artificial intelligent and engineering educations (renewable energy) 